\title{
Relationship between the Social Cognition and Object Relations Scale (SCORS) and Attachment Style in a Clinical Sample
}

\author{
Michelle B. Stein ${ }^{1 *}$, Caleb J. Siefert ${ }^{2}$, Rosemarie Vala Stewart ${ }^{3}$ and \\ Mark J. Hilsenroth ${ }^{3}$ \\ ${ }^{1}$ Massachusetts General Hospital and Harvard Medical School, Boston, \\ Massachusetts, USA \\ ${ }^{2}$ University of Michigan-Dearborn, Dearborn, Michigan, USA \\ ${ }^{3}$ Derner Institute of Advanced Psychological Studies, Adelphi University, Garden City, New York, USA
}

\begin{abstract}
This present study examined the relationship between the Social Cognition and Object Relations Scale (SCORS) and two measures of adult attachment: the Relationship Questionnaire (RQ) and the Experiences in Close Relationships Questionnaire-Revised (ECR-R). Forty-five patients ( $76 \%$ female) at a university-based outpatient treatment clinic participated in this study. We hypothesized that higher levels of attachment security would be associated with higher, more adaptive ratings on the SCORS variables. Results indicated that the SCORS Self-Esteem (SE) variable was significantly positively related to the RQ's Secure Attachment ratings and negatively related with the ECR-R's Anxious Attachment scale. Additionally, negative trends were noted between SE and the RQ's Fearful and Preoccupied Attachment scores. The SCORS Emotional Investments in Relationships and Affective Quality of Representations variables were associated with higher Secure scores and lower, more maladaptive Preoccupied scores on the RQ. It was also associated with greater attachment anxiety as measured by the ECR-R. Using both clinician (SCORS) and participant-rated measures (ECR-R and $R Q$ ), this study provides further understanding on how object representations and attachment style relate within a clinical sample. Results are discussed in light of prior research examining relationships between object relations and adult attachments, and clinical implications are also reviewed. Copyright (C) 2010 John Wiley \& Sons, Ltd.
\end{abstract}

Key Practitioner Message:

- Individuals with higher levels of attachment anxiety may enter therapy with more self-image problems.

- Individuals with higher levels of attachment anxiety may enter therapy with more maladaptive expectations about relationships.

- Patients who endorse high levels of attachment anxiety (e.g., fearful and preoccupied) may be more likely to present with Axis II complaints.

- Examining a patient's attachment style and object relations using different measures of assessment (e.g., explicit and implicit) can help gain a deeper and more comprehensive understanding of a patient.

Keywords: SCORS, Attachment, Object Relations, RQ, ECR-R, Social Cognition

\section{INTRODUCTION}

There are a number of theoretical similarities between object relations theory and attachment theory (Levy, Blatt, \& Shaver, 1998; Shaver \& Mikulincer, 2002). Both hypoth-

\footnotetext{
${ }^{*}$ Corresponding to: Michelle B. Stein, Ph.D., Massachusetts General Hospital and Harvard Medical School, Psychology Assessment Center, 1 Bowdoin Square, Suite 701, 7th Floor, Boston, MA 02114-2919, USA. E-mail: mstein3@partners.org

An earlier version of this paper was presented at the annual meeting of the Society for Personality Assessment, San Diego, CA, March 2006.
}

esize that early relationships with caregivers come to influence how we think about ourselves and others. The quality and nature of these relational interactions with caregivers becomes internalized within the individual. These internalized representations guide how individuals perceive, conceptualize and experience relationships (Levy et al., 1998). These representations are composed of cognitive, affective, motivational and behavioural elements that serve as mental models or schemas for relationships and interpersonal experiences (Diamond \& Blatt, 1994; Levy et al., 1998; Slade \& Aber, 1992). Parentchild relationships have a strong influence on the 
development of these models, and both theories hold that experiences of reunion, separation and loss play a role in the formation (and activation) of these models (Steele \& Steele, 1998). In addition to theoretical similarities, both the attachment theory and the object relations theory have informed conceptualizations of psychopathology (e.g., Blatt \& Levy, 2003) and psychotherapeutic practices (e.g., Farber, Lippert, \& Nevas, 1995; Grotstein, 1990; McWilliams, 1994; for a review of similarities and differences between the object relations theory and the attachment theory, see Levy et al., 1998).

Despite the similarities just discussed, data suggest that the constructs tapped by the object relations theory and those of the attachment theory are related but distinct (Buelow, McClain, \& McIntosh, 1996; Priel \& Besser, 2001). Thus, it is important to examine associations between the two fields to better understand how they are related (Cassidy, 2002). The present paper examines how attachment-based concepts (e.g., attachment anxiety and avoidance; prototypical patterns of attachment) relate to conceptualizations of important aspects of object relations representations (e.g., complexity of representations, affective tone of representations) using a clinical sample of patients entering psychotherapy. The focus of this study is to examine how unique cognitive and affective aspects of object representations relate to patterns of attachment in adults.

Although a number of authors (e.g., Calabrese, Farber, \& Westen, 2005; Cassidy, 1998; Levy et al., 1998; Steele \& Steele, 1998) have called for studies exploring the relationships between the attachment theory and object relations, to date, only a few studies have tackled this topic directly. Levy et al. (1998) examined the relationship between selfreported adult attachment style and the quality of internal representations for parents in a non-clinical sample of college students. Adult attachment styles were assessed using self-report measures (Bartholomew \& Horowitz, 1991; Hazan \& Shaver, 1987). Representations for parents were assessed using the structural dimensional approach developed by Blatt and colleagues (1992) in which participants write narratives describing their parents. Attachment patterns were assessed by asking participants to rate how well three attachment prototype descriptions (Secure, Preoccupied, Dismissive) described them on a 1 to 7 scale. Results revealed, as expected, differences in the quality and nature of representations across the four attachment classifications. Securely attached participants' parental representations had higher levels of differentiation and elaboration, and parents were rated higher in benevolence and lower in punitiveness. By contrast, dismissing participants' representations were lower in differentiation, and they described parents as more punitive and malevolent. Preoccupied participants' representations involved high levels of ambivalence, and they described their parents as high in both benevolence and punitive- ness. Fearful participants described their parents as punitive and malevolent, but surprisingly showed high levels of differentiation and conceptual complexity.

Using similar methods as Levy et al.'s (1998) for assessing the quality of object relations (i.e., Blatt et al., 1992), Priel and Besser (2001) examined associations among adult attachment, internal representations and antenatal attachment in a sample of pregnant women. In this study, 120 pregnant women in their third trimester (with no psychiatric history) completed the Relationship Questionnaire (RQ; Bartholomew \& Horowitz, 1991) and produced narrative accounts describing their mothers that were coded for object relations (i.e., emotional tone, complexity, integration). They also completed a selfreport rating assessing antenatal attachment to their unborn baby. Results indicated that mothers who rated themselves as securely attached had less ambivalence, described their mothers more positively and had more complex, differentiated and integrated internal representations of their own mothers. Interestingly, complexity of internal representations also significantly differentiated between insecure groups. These results are similar to those obtained by Fonagy, Steele, and Steele (1991) who demonstrated that expecting mothers' Adult Attachment Interview status predicted their child's attachment status (as determined by the Strange Situation) at a 1-year follow-up.

As with Levy et al. (1998), fearfully attached participants were closest to the secure group regarding complexity of representations. Dismissing women had the least complex representations. Of note, in this study, object relations were found to mediate the relationship between mothers' attachment style and reported antenatal attachment to their unborn infant, suggesting that although attachment constructs and object relations overlap, they are also likely tapping some clearly distinctive content.

In a later study, Calabrese et al. (2005) examined associations between adult attachment and object representations of the self and others using a multi-item self-report measure of adult attachment and narrative measure of object relations. In this study, college students completed the Reciprocal Attachment Scale (West, Sheldon, \& Reiffer, 1987; West \& Sheldon-Keller, 1994) and were asked to write 11 narratives (including three that asked for interactions with their father and mother [most painful; most typical; most comforting]; two involving typical interactions with their significant other; and three interactions that were representative of the self [an incident typical of the self; an incident that shaped identity and an incident where the participant felt bad about the self]). These narratives were scored using the Social Cognition and Object Relations scale for Interview and Narrative data (SCORS; Westen, Barends, Leigh, Mendel, \& Silbert, 1994). As expected, a number of relationships between Internal Working Models 
(IWMs) and object relation representations were found. For example, higher levels of attachment security (i.e., having a sense that others are available as a secure base in times of need) were associated with higher levels of complexity and differentiation in object representations, increased ability to recognize and show emotional concern for others and enhanced ability to read social situations. In addition, higher levels of coherence of narrative, adaptive management of aggressive impulses and positive selfrepresentations were associated with higher levels of attachment security.

While the strengths of the previous studies examining associations between object relations and adult attachment are many, there are ways in which this line of research could be improved. For example, current data focusing on the measurement of attachment (e.g., Fraley \& Spieker, 2003; Fraley \& Waller, 1998) suggest that adult attachment is best conceptualized along two dimensions (e.g., anxiety and avoidance). However, few studies have examined associations between attachment dimensions and object relations using attachment inventories explicitly designed for this measuring attachment dimensions. Furthermore, while clinical implications have been drawn from the studies described above, it is difficult to determine the extent to which findings comparing the object relation theory and the attachment theory arising from non-clinical populations generalize to clinical settings.

The present study addresses a number of gaps in the literature by examining associations between the structure of internal representations (as determined through a narrative-based task) and adult attachment (using self-rated measures of attachment style and attachment dimensions) in a clinical sample of individuals seeking psychotherapy. Given that prior research into object relations and the attachment theory has generally been conducted with categorical measures, we have decided to assess adult attachment using both a more categoricalbased measure (consistent with prior research; e.g., Levy et al., 1998) and a dimensional measure of attachment anxiety and avoidance. We expected that Secure attachment (Low Avoidance, Low Anxiety) would be positively related to Complexity of Representations (COM), Affective Quality of Representations (AFF), Emotional Investments in Relationships (EIR) and Understanding of Social Causality (SC). In contrast, we expected that preoccupied attachment and higher scores for attachment anxiety would be negatively associated with AFF, COM and EIR. Finally, we expected dismissive attachment and higher scores on attachment avoidance to be negatively associated with COM and EIR. While previous studies have found higher COM for fearful individuals, we questioned if this relationship would be found in a clinical sample. Thus, we did not make hypotheses related to fearful attachment. This is only the second study to utilize the
SCORS in relation to attachment and the first to do so in a clinical sample. As such, we wanted to compare any similarities that existed between Calabrese et al.'s (2005) non-clinical sample versus our clinical sample.

\section{METHOD \\ Participants}

Participants included 45 patients at a university-based outpatient treatment clinic. As can be observed in Table 1 , patients were predominantly female and single. The mean age for the sample was 30.3 (standard deviation $[\mathrm{SD}]=12.6$ ). This sample consisted of primarily mooddisordered patients with relational problems manifested in either Axis II, or subclinical features of Axis II.

\section{Procedure}

Patients entering treatment were asked to participate in a research project, and no one was excluded based on a particular diagnosis or comorbidity. Therapists were assigned cases based on availability and caseload as it is routine practice for an outpatient clinic. Patients who agreed to participate in this project filled out an informed consent prior to engaging in the research study.

The clinicians who conducted the psychological assessment and psychotherapy sessions were 18 advanced

Table 1. Demographic information $(N=45)$

\begin{tabular}{lcc}
\hline Variable & $\mathrm{N}$ & $\%$ \\
\hline Gender & 34 & 76 \\
$\quad$ Female & 11 & 24 \\
Male & 30.3 & 12.7 \\
Mean age (SD) & & \\
Marital status & 32 & 71 \\
Single & 9 & 20 \\
Married & 4 & 9 \\
Divorced & & \\
Primary Axis I diagnosis & 5 & 11 \\
Adjustment disorder & 7 & 15 \\
Anxiety disorder & 2 & 4 \\
Eating disorder & 21 & 47 \\
Mood disorder & 10 & 22 \\
V code relational problem & 27 & 60 \\
Axis II diagnosis & 11 & 24 \\
Axis II trait/features & Mean \\
Psychiatric severity & 59.5 & 4.9 \\
Intake axis V GAF & 1.0 & 5 \\
SCL-GSI (SD) & & \\
\hline
\end{tabular}

$\mathrm{SD}=$ standard deviation, GAF = Global Assessment Functioning, SCL-GSI = Global Severity Index of the Symptom Checklist-90 Revised. 
doctoral students (nine male and nine female) enrolled in an American Psychological Association (APA)-accredited Clinical Ph.D. program. The clinicians who completed the assessment received a minimum of 3.5 hours of supervision per week on assessment data, clinical interventions, organization of feedback session and weekly review of videotaped case material. The psychological assessment consisted of four steps including three meetings between the patient and clinician, and one patient appointment to complete a battery of self-report measures. The three meetings included (1) a semi-structured diagnostic interview and early memory protocol; (2) interview follow-up and (3) a collaborative feedback session. Each videotaped semi-structured clinical interview lasted approximately 2 hours and focused on a number of salient therapeutic topics such as presenting problems; past psychiatric and medical history; family history; developmental, social, educational and work history; an exploration of both historic and current relational episodes; and a mental status exam that included an assessment of all Diagnostic Statistical Manual Fourth Edition (DSM-IV) symptom criteria for schizophrenia, major depressive/ manic/mixed episode, dysthymia as well as many anxiety symptoms. After the clinical interview, each participant received an interpretive/feedback session lasting 1-1.5 hours, also videotaped and organized according to the Therapeutic Model of Assessment (Finn \& Tosanger, 1992, 1997; Fischer, 1994). Further details of the methodology and procedures used in this assessment process are described more fully elsewhere (see Hilsenroth, 2007).

SCORS raters were advanced graduate students enrolled in an APA-approved Clinical Psychology doctoral program. SCORS ratings provided by the clinician were based on the patient's level of relational functioning at the time of evaluation (e.g., semi-structured interview and feedback) and across the first two sessions of psychotherapy (when available). The SCORS variables were dimensionally scored based on relational episodes and self-statements verbally expressed directly to the clinician during the course of the psychological evaluation and the first two sessions of psychotherapy. External raters then independently rated the SCORS variables for each participant immediately after viewing videotapes of the clinical interview, feedback and first two psychotherapy sessions (when available). External raters in this study consisted of the same pool of doctoral-level graduate clinicians trained in the SCORS rating system (none provided video ratings for their own patients) or in some cases the study supervisor (a licensed doctoral clinical psychologist; Peters, Hilsenroth, Eudell-Simmons, Blagys, \& Handler, 2006). Details regarding the establishment of the SCORS inter-rater reliability obtained in this study are described elsewhere (Peters et al., 2006). Patients devoted one session during the psychological assessment phase of treatment to complete a battery of self report measures including the RQ (Bartholomew \& Horowitz, 1991) and Experiences in Close Relationships Questionnaire, Revised (ECR-R; Fraley, Waller, \& Brennan, 2000).

\section{Assessment Measures}

SCORS-Global Ratings (Hilsenroth, Stein, E Pinsker, 2007; Westen 1995)

The SCORS consists of eight variables that are scored on a seven-point anchored scale in which lower scores (e.g., 1, 2 or 3) indicate more pathological responses and higher scores (e.g., 5, 6 and 7) indicate healthy responses. The eight variables are COM, AFF, EIR, Emotional Investment in Values and Moral Standards (EIM), SC, Experience and Management of Aggressive Impulses (AGG), Self-esteem (SE) and Identity and Coherence of Self (ICS). Specifically, COM evaluates how well the patient is able to see internal states (i.e., thoughts and feelings) in the self and other when reporting narratives. In addition, COM assesses the patient's relational boundaries and ability to integrate both positive and negative aspects of self and others. AFF examines a patient's expectations of others within a relationship and the description of significant relationships in the past. EIR assesses a patient's ability for intimacy and emotional sharing. EIM assesses the extent to which the patient utilizes abstract thought in relation to morality and compassion for others. SC assesses the extent to which the patient understands human behaviour. AGG assesses the patient's ability to tolerate and manage aggression appropriately. SE assesses the patient's self-concept, and ICS assesses a patient's level of fragmentation and integration. More thorough descriptions of the eight SCORS variables, global rating method and various training examples are provided in the manuals developed by Hilsenroth et al. (2007) as well as Westen (1995).

\section{RQ (Bartholomew \& Horowitz, 1991)}

The RQ is a self-report measure that asks participants to read four paragraphs, each describing a prototypical attachment style, and to indicate how well each paragraph describes them. They are asked to rate on a sevenpoint scale the degree to which each style pertains to them where a score of 1 is 'not at all like me', a score of 4 is 'neutral/mixed' and a score of 7 is 'very much like me'. The attachment styles assessed are secure, dismissing, preoccupied and fearful. Individuals with Secure attachments are comfortable in close relationships and have an internalized sense of self-worth. They feel secure in relationships and can adaptively cope with loss and separations without deactivating affect to deny losses or become preoccupied with the loss to the exclusion of other activities. They are able to form bonds and appropriately mourn when those bonds are broken. Individuals with preoccupied attachments anxiously attempt to gain attention and affection from others. They have tremendous 
difficulty coping with loss and separation. Individuals with fearful attachments feel simultaneously dependent on others acceptance of him or her, but also feel that others will eventually let them down. They long for closeness, but tend to avoid intimacy due to feared rejection and loss. Forming relationships and coping with loss and separations are difficult for them. Lastly, individuals with dismissing attachments avoid intimacy and closeness in general, but maintain their sense of self-efficacy by denying the value of close relationships (Bartholomew \& Shaver, 1998). They have difficulty establishing relationships and tend to view independence and autonomy as more valuable than relationships. They tend to cope with losses and separations by denying the importance of attachments and turning their attention elsewhere.

\section{ECR-R (Fraley et al., 2000)}

The ECR-R assesses attachment anxiety (e.g., strong need for care and attention from attachment figures combined with an uncertainty about the willingness or capability of attachment figures to respond to him/her in an appropriate fashion; Rholes \& Simpson, 2004, p. 4) and avoidance (e.g., discomfort with intimacy and need for independence, even in close relationships; Rholes \& Simpson, 2004, p. 4) dimensions. It is a 36-item questionnaire where participants are asked to rate statements based on how they generally feel in emotionally close romantic relationships. The seven categories range from 'strongly disagree' to 'strongly agree'. Fraley and colleagues have presented considerable evidence that the four-category model of attachment is best characterized by the two-dimensional system. Secure adults are low in both attachment anxiety and attachment avoidance. Preoccupied adults are high in attachment anxiety and low in attachment avoidance. Dismissive adults are high in attachment avoidance and low in attachment anxiety. Fearful adults are high on both dimensions.

\section{RESULTS}

\section{Inter-rater Reliability}

SCORS ratings of relational episodes expressed during the assessment phase and first two sessions of treatment were calculated using intraclass correlation coefficients (ICCs). We used the Spearman Brown corrected one-way random effects model $(1,2)$, which represents the average of the two raters used in the study. Shrout and Fleiss (1979) report the magnitude for interpreting ICC values in which poor is $<0.40$, fair $=0.40$ to 0.59 , good $=0.60$ to 0.74 and excellent $=>0.74$. We achieved excellent reliability on AFF (0.83) and SE (0.82), good reliability on AGG $(0.67)$ and fair reliability on SC (0.57), EIR (0.55) and COM (0.54). We did not obtain greater than 0.40 reliability on EIM and ICS. This is considered poor reliability, and as a
Table 2. Means and standard deviations of the SCORS, EC-R and RQ

\begin{tabular}{lcc}
\hline & Mean & SD \\
\hline SCORS variable & & \\
Complexity & 3.9 & 0.75 \\
Affect & 3.2 & 0.85 \\
Relationships & 3.5 & 0.80 \\
Causality & 3.7 & 0.77 \\
Aggression & 3.9 & 1.00 \\
Self-esteem & 3.1 & 0.68 \\
RQ variables & & \\
Secure & 4.04 & 1.78 \\
Fearful & 4.69 & 1.94 \\
Preoccupied & 3.87 & 2.08 \\
Dismissing & 3.42 & 1.59 \\
ECR-R variables & & \\
Anxious & 3.76 & 1.12 \\
Avoidant & 3.55 & \\
\hline
\end{tabular}

SCORS = Social Cognition and Object Relations Scale, ECR-R = Experience in Close Relationships Questionnaire-Revised, RQ $=$ Relationship Questionnaire.

result, these two variables were not included in analyses.

\section{Descriptive Data}

The means for the SCORS variables in Table 2 reflect a mild to moderate range of pathology (e.g., 3-4) within the sample of psychotherapy narratives. This range of pathology may manifest in less mature and increased negative relationship patterns, more simplistic representations of the self and other as well as lower self-esteem than scores in the 5 to 6 range. These scores are consistent with previous research that used outpatient populations (Ackerman, Clemence, Weatherhill, \& Hilsenroth, 1999). Our ECR-R anxious mean (3.76) is consistent with normative means; however, our avoidant mean (3.55) is slightly higher $(N=$ 22000; http:/ / www.psych.uiuc.edu/ rcfraley/measures / ecrr.htm; 3.64 and 2.93, respectively). In addition, our RQ means (see Table 2) were consistent with the normative means for the USA-Northeast sample ( $N=228$; Secure: mean $=4.23, \mathrm{SD}=1.58$; Dismissing: mean $=3.94, \mathrm{SD}=1.73$; Preoccupied: mean $=3.32, \mathrm{SD}=1.79$; Fearful: mean $=3.80$, $\mathrm{SD}=2.00$; see Schmitt et al., 2004 for details regarding normative data).

\section{Intercorrelations between the SCORS and RQ Attachment Prototypes (See Table 3)}

We initially hypothesized that the higher levels of attachment security would be associated with higher, more 
Table 3. Relationship comparing SCORS-combined scores with the RQ

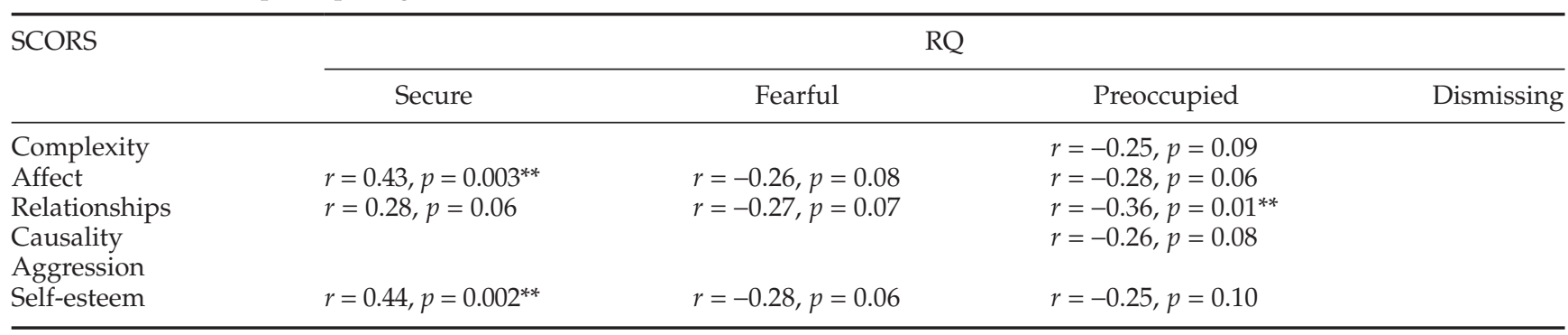

$N=45 ;{ }^{* *}$ correlation is significant at the 0.01 level (two-tailed).

$\mathrm{SCORS}=$ Social Cognition and Object Relations Scale, $\mathrm{RQ}=$ Relationship Questionnaire .

Complexity = complexity of representations, Affect $=$ affective quality of representations, Relationships = emotional investment in relationships,

Causality = understanding of social causality, Aggression = experience and management of aggressive impulses.

adaptive SCORS ratings. We also hypothesized that the scores for the RQ's Preoccupied Attachment prototype would be associated with lower, more maladaptive SCORS ratings on COM, AFF, and EIR. Finally, we anticipated that greater degrees of avoidance and dismissiveness (i.e., higher scores for the RQ's Fearful and Dismissing Attachment prototypes) would be associated with lower, more maladaptive SCORS ratings on COM and EIR.

As can be seen in Table 3, a significant positive relationship between SCORS AFF and scores for the RQ's Secure Attachment prototype $(r=0.43, p=0.003)$ were found. Participants who rated the RQ's Secure Attachment pattern as more descriptive of themselves tended to produce narratives that were rated as higher (i.e., more adaptive) on the SCORS AFF variable. A negative relationship was also found between AFF and the RQ's Preoccupied and Fearful Attachment prototype scores. However, these relationships only reached the status of a statistical trend and did not fully reach significance. A significant negative relationship was found $(r=-0.36, p=0.01)$ between the SCORS EIR variable and scores for Preoccupied Attachment prototype on the RQ. Participants who rated the RQ's Preoccupied Attachment prototype as more descriptive of themselves tended to produce narratives that scored lower (i.e., more maladaptive) on the EIR variable. As would be expected, a positive trend toward significance was noted between EIR and the RQ's Secure Attachment style, while a negative trend was noted with Fearful Attachment style. A significant positive correlation was found between SE and Secure Attachment $(r=0.44, p=0.002)$, with participants rating the Secure Attachment paragraph as more descriptive of them producing higher SE scores. Negative relationships between SCORS SE and both the Fearful and Preoccupied Attachment scores were observed, although these only achieved a magnitude to suggest a statistical trend (i.e., $p<0.10)$. Lastly, a negative trend toward significance was noted between Preoccupied Attachment and SC. There were no significant correlations or trends noted between the SCORS and the RQ's Dismissing Attachment.
Table 4. Relationship comparing SCORS-combined scores with the ECR-R scales

\begin{tabular}{|c|c|c|}
\hline \multirow[t]{2}{*}{ SCORS } & \multicolumn{2}{|c|}{ ECR-R scales } \\
\hline & Anxious & Avoidant \\
\hline Complexity & NS & NS \\
\hline Affect & $-0.50^{*}$ & NS \\
\hline Relationships & $-0.35^{* *}$ & NS \\
\hline Causality & NS & NS \\
\hline Aggression & NS & $-0.28^{* * *}$ \\
\hline Self-esteem & $-0.46^{*}$ & NS \\
\hline \multicolumn{3}{|c|}{$\begin{array}{l}N=45 ;{ }^{*} p<0.01 ;{ }^{* *} p<0.05 ;{ }^{* * *} p<0.10 . \\
\text { NS = not significant; SCORS = Social Cognition and Object Relations } \\
\text { Scale, ECR-R = Experience in Close Relationships Questionnaire- } \\
\text { Revised. } \\
\text { Complexity = complexity of representations, Affect = affective quality of } \\
\text { representations, Relationships = emotional investment in relationships, } \\
\text { Causality = understanding of social causality, Aggression = experience } \\
\text { and management of aggressive impulses. }\end{array}$} \\
\hline
\end{tabular}

\section{Intercorrelations between the SCORS and ECR-R (See Table 4)}

We initially hypothesized that the ECR-R's Attachment Anxiety dimension would be associated with lower ratings (i.e., more pathological) on COM, AFF, EIR, AGG and SE and that the Attachment Avoidance dimension would be associated with lower (i.e., more pathological) ratings on AFF, EIR and SE. Attachment Anxiety was significantly negatively correlated with AFF $(r=-0.50, p$ $=0.000), \operatorname{EIR}(r=-0-.35, p=0.02)$ and SE $(r=-0.46, p=$ $0.00)$. That is, individuals that rated themselves as higher on Attachment Anxiety had lower, more maladaptive AFF, EIR and SE scores. There was a negative trend toward significance regarding the relationships between the Attachment Avoidance dimension and Aggressive Impulses, indicating that those that rated themselves as avoidantly attached were rated as having lower, more maladaptive AGG scores. 
Table 5. Relationship comparing RQ with the ECR-R scales

\begin{tabular}{lcc}
\hline RQ & \multicolumn{2}{c}{ ECR-R } \\
\cline { 2 - 3 } & Anxious & Avoidant \\
\hline Secure & $-0.55^{*}$ & $-0.41^{*}$ \\
Fearful & $0.49^{*}$ & $0.42^{*}$ \\
Preoccupied & $0.44^{*}$ & $\mathrm{NS}$ \\
Dismissing & $\mathrm{NS}$ & $0.35^{* *}$ \\
\hline
\end{tabular}

$N=44 ;{ }^{*} p<0.01 ;{ }^{* *} p<0.05$. NS $=$ not significant.

\section{Intercorrelation between the $R Q$ and ECR-R (See Table 5)}

As stated previously, we included two measures of adult attachment in order to stay consistent with prior research examining object relations and the attachment theory while simultaneously taking advantage of recent developments in the self-report measurement of attachment in adults. This afforded us the opportunity to examine the extent to which these two widely used self-report measures of attachment agree within our sample. As expected, the RQ's Secure Attachment was significantly inversely related with both attachment anxiety $(r=-0.55, p=0.00)$ and attachment avoidance $(r=-0.41, p=0.01)$. The RQ's Fearful Attachment was significantly positively related to both the ECR-R's Attachment Anxiety $(r=0.49, p=0.00)$ and Attachment Avoidance $(r=0.42, p=0.00)$. The RQ's Preoccupied Attachment was significantly positively correlated with the ECR's Attachment Anxiety dimension $(r=0.44, p=0.00)$. Lastly, the RQ's Dismissing Attachment was positively related to the ECR's Attachment Avoidance dimension $(r=0.35, p=0.02)$. In short, all relationships between the ECR-R and the RQ scores were as would be expected given current conceptualizations of the selfreport measurement of adult attachment (Brennan, Clark, \& Shaver, 1998; Shaver \& Mikulincer, 2002).

\section{DISCUSSION}

The present study assessed the relationship between patients' object representations (e.g., SCORS ratings of psychotherapy narratives) and self-reported attachment style (e.g., RQ and ECR-R) in a clinical sample. The findings from this study indicate that patients who rated themselves as securely attached had more positive expectations of relationships and experienced significant others more favorably. In addition, they described themselves in a more positive and adaptive fashion. On a whole, these results are generally consistent with prior research focusing on the relationships between attachment and object relations (Blatt et al., 1992; Calabrese et al., 2005; Priel \& Besser, 2001). Together, this body of work suggests that across clinical and non-clinical samples, individuals with higher levels of attachment security are not only more open to the idea of relationships but are more likely to hold positive expectations for relationships and others. In psychotherapy, individuals with higher levels of attachment security are thus also more likely to have more positive expectations for forming relationships with the therapist and others in their life. These findings couple well with research linking Secure Attachment patterns in patients to the formation of a strong working alliance (Eames \& Roth, 2000; Mallinckrodt, Gantt, \& Coble, 1995; Mallinckrodt, Porter, \& Kivlighan, 2005).

Patients who rated themselves as having a preoccupied/anxious attachment had a tendency to view relationships in a less invested and more maladaptive fashion (EIR). Participants scoring higher in Attachment Anxiety on the ECR-R also described significant others as more malevolent (AFF) and were rated as having a lower sense of self-worth (SE). Lower, more maladaptive ratings on AFF, EIR and SE are consistent with past research demonstrating that preoccupied/anxiously attached individuals tend to be more affectively laden (e.g., sadness) around loss and have a number of fears regarding their ability to sustain relationships. This can result in more clinging and controlling behaviours. In addition, they often view their self-worth in relation to others responding to them with love and support (Calabrese et al., 2005; Carnelley, Pietromonaco, \& Jaffe, 1994; Collins \& Read, 1990; Keelan, Dion, \& Dion, 1998; Levy and Davis, 1998; Mikulincer \& Nachshon, 1991; Mikulincer \& Orbach, 1995; Mikulincer, Orbach \& Iavnieli, 1998; Pistole, 1989; Shaver \& Mikulincer, 2002). A limited negative relationship was found between the RQ's Preoccupied Attached and SCORS SC, suggesting that these patients had a more difficult time describing interpersonal events in logical, organized and coherent fashion. It is possible that preoccupied individuals experience such anxiety surrounding sustaining relationships, that their ability to view interpersonal events in a fashion similar to how most adults would view them is reduced (e.g., increased distortion). Their preoccupation with maintaining relationships (and inversely their intense fears regarding loss) may result in failures to correctly ascertain other's intentions. In addition, they may be more likely to misperceive the meanings of other people's actions. There was no developmental component to the present study. Nonetheless, prior research in attachment provides a context for thinking about the current findings (see Mikulincer \& Shaver, 2003). Adults with higher levels of attachment security are more likely to have had a history of relational experiences with their significant others in which they felt supported, validated and free to explore the world and themselves. They are more likely to have had experiences in which others were available when needed and capable of providing support and assistance, without being overbearing. This is expected to result in internalizations of 
others and relationships in a more positive manner. Object Relations Theory would also suggest that individuals who have internalized/more positive and mature representations of others would also be more likely to be capable of forming trusting and adaptive relationships as adults. Thus, one would expect that secure attachments and internalized representations for others would be related, as data suggest here. Given the correlational nature of the present study, our results do not suggest that Secure Attachment causes positive internalized representations, or vice versa. They merely suggest that the two are likely to co-occur as both theories would predict. It is likely that having positive representations of others and relationships provides one with a greater willingness to enter relationships, seek assistance when needed and be open to others, all of which, in turn, may further foster a sense of security. The present results suggest that these relationships between Secure attachments and positive representations of others and relationships in general continue to exist even when the individual is in distress (as was the case here with patients presenting for psychotherapy). In considering the clinical ramifications of this, such individuals are likely to enter therapy with the ability to form a therapeutic bond and a willingness to view the therapist as helpful and well intentioned despite their present level of difficulty. They are also more likely to be willing to seek support outside of the therapeutic encounter. Even when distressed, patients in our sample continued to evidence positive representations of others and relationships. Such assets may be leveraged by the therapist to establish the therapeutic relationship, validate additional support seeking efforts and provide a base from which the patient can explore their distress and difficulties.

The attachment theory also holds that adults with higher levels of attachment anxiety have more experiences with their significant others that left them feeling invalidated, unsupported and/or that important others would not be there during times of need. One's self-esteem can become compromised when caregivers are not attuned to a patient's needs, especially when feeling a sense of threat or danger in the world (Ainsworth, 1982, 1989; Ainsworth, Blehar, Waters, \& Wall, 1978; Bowlby, 1973, 1977, 1980, 1982; Carnelley et al., 1994; Collins \& Read, 1990; Fraley \& Shaver, 1998; Levy \& Davis, 1988; Pistole, 1989; Mikulincer et al., 1998; Shaver \& Mikulincer, 2002, 2005). This combination, low self-esteem and fear that others will be unavailable when needed, can result in notable anxiety as the individual fears that he or she will not have access to the other during times of need and tends to anticipate that they will be unable to manage the situation on their own. This can produce rather animated attempts to keep significant others within reach in more anxiously attached individuals. This can culminate in quite complex feelings about others and relationships. On one hand, there is a longing for support, protection and care afforded by others. On the other hand, there is resentment of others' needs for autonomy and chronic fears that others will leave them or let them down. Thus, their preoccupation with relationships is, in part, based more on an antagonistic functional dependency as opposed to a true desire for relatedness between equals. As such, they often experience an angry preoccupation with significant others and conflictual feelings about partners, and tend to be hypervigilent for cues that others are leaving or may be unavailable (Kobak et al., 1993). As such, it is of little surprise that their internal representations for others tend to be more malevolent, and their ability to invest in relationships emotionally is less mature. This is consistent with the present findings. In addition, the inverse relationship between internalized positive self representations (i.e., self-esteem) and anxious attachments is also consistent with what would be expected. This combination of negative self-representations, limited capacity for investing emotionally in relationships and more malevolent representations for others are likely to be coupled with attempts to maintain closeness despite intense feelings of being let down and powerful fears of abandonment. In the clinical setting, such individuals may present with unrealistic expectations for therapy, anticipation that the therapist will abandon them or fail to assist them and greater intensity of emotions surrounding patient-therapist interactions (see Holmes, 2010). Therapists will need to handle treatment ruptures with care, may need to work to increase such individuals capacity for relatedness and attempt to help such individuals cultivate a more positive, agentic sense of self.

While findings with regard to Secure and Preoccupied attachments tended to be consistent with prior research using non-clinical samples, there were also some findings that were not in accordance. We did not find that COM was positively correlated with Fearful Attachment as with prior research (Blatt et al., 1992; Levy et al., 1998). In the present study, patients who rated themselves higher on the RQ's Fearfully Attached prototype did not describe other people (or themselves) in more differentiated ways. Instead, our results tended to indicate that fearful attachment was more associated with less differentiated representations of self and others. One possible explanation for the discrepancy between our findings and those of Levy et al. (1998) is the use of a clinical sample. That is, often times, people seek out psychotherapy because they are struggling with understanding themselves and others in a complex and nuanced fashion, which subsequently lead to relational difficulties. Furthermore, the present study made use of a sample in which many patients were experiencing some Axis II traits. Prior research with the SCORS (e.g., Ackerman et al., 1999; Stein, Pinsker, \& Hilsenroth, 2007) has indicated that patients with Axis II traits or disorders tend to have lower COM scores on the SCORS relative to patients without Axis II traits and non-clinical 
samples. In the attachment literature, fearful and preoccupied styles of attachment have also been associated with Axis II pathology (Agrawal et al., 2004). Thus, these two lines of research may suggest that in clinical settings individuals with greater levels of attachment anxiety (i.e., Fearful and Preoccupied attachments) may be more likely to present with Axis II complaints. Additionally, research with the SCORS has tended to suggest that patients with Axis II complaints are less likely to have well-differentiated self-other boundaries and view others in less complex terms. These lines of inquiry may help to illuminate our findings in the present study. Namely, in our clinical sample composed of several individuals with Axis II traits, the relationship between attachment anxiety and $\mathrm{COM}$ was negative. It is possible that in non-clinical samples where individuals high in attachment anxiety are nonetheless free from Axis II qualities, associations between Fearful attachments and COM may be different as was the case in Levy et al. (1998).

No significant relationships between the RQ's Dismissing Attachment prototype and the SCORS variables were observed in the present study. Similarly, no relationships were observed for the Attachment Avoidance dimension from the ECR-R and the SCORS variables. These findings are generally consistent with Calabrese et al.'s (2005) study. However, they are in contrast to Blatt et al.'s (1992) and Levy et al.'s (1998), who found more simplistic representations of people and decreased investment in relationships for dismissive types. The present study did reveal a limited relationship between the SCORS AGG variable and ECR-R Attachment Avoidance scores, although this relationship failed to reach statistical significance. This may make conceptual sense because avoidant individuals are more likely to anticipate and be sensitive to aggression and harm (not necessarily physical), which inclines them to avoid intimacy in relationships (Bartholomew \& Shaver, 1998). Crawford et al. (2006) found some limited relationships between interpersonal aggression and avoidant attachment $(r$-values ranged from 0.24 to 0.34 ). Still, given the limited nature of the relationship between Attachment Avoidance and AGG observed in this study, further research is needed to substantiate these conclusions in clinical samples.

Other patterns were associated with SCORS variables: AFF and EIR across Secure, Preoccupied and Anxious attachments. This is consistent with attachment research that shows the ability to count and rely on caregivers in times of need relates to how significant relationships are experienced and how invested he or she is in others and relationships as adults. That is, there is going to more negative emotions experienced in adult relationships surrounding perceptions and intentions of other people if caregivers responded in a more pathological fashion with respect to emotional availability, consistency, attentiveness and reactivity to the child's needs (Ainsworth, 1982,
1989; Ainsworth et al., 1978; Bowlby, 1973, 1977, 1980, 1982; Calabrese, Farber \& Westen, 2005; Carnelley, Pietromonaco, \& Jaffe, 1994;Collins \& Read, 1990; Fraley \& Shaver, 1998; Levy \& Davis, 1988; Pistole, 1989; Shaver \& Mikulincer, 2002).

The present study may also have implications for psychotherapy. For example, patients who were anxiously attached had more maladaptive expectations and investments in relationships. They also exhibited a lower sense of self-worth. Therefore, the therapist can be mindful of ways in which these aspects of object relations manifest during the course of therapy. A therapist might adjust therapeutic interventions and therapist behaviours, and pay closer attention to how these three variables might impact her/his ability to optimally benefit from therapy. In addition, this provides a more complex view of how a person's object relations within a given attachment style impacts his/her ability to maintain mutually satisfying relationships outside the therapy. Knowing this information early on in treatment can help the therapist hone in on important areas of focus and reduce hindrances to treatment. Building on this, using the SCORS can also enable clinicians to monitor the patient's object relations dimensionally throughout treatment to see if there are adaptive changes (e.g., increased self-esteem and increased expectations and investment in relationships) across treatment. This is consistent with Davila and Levy (2006) who pointed out that one of the main objects of psychotherapy from an attachment perspective is to work on the patients' internal working models to make their attachment style more flexible and adaptive (Eagle, 2006). However, assessing this may not always be easy. For example, Makinen and Johnson (2006) did not find any significant group differences in attachment dimensions as measured by the ECR-R across 13 sessions of treatment. They suggest that attachment styles are 'enduring characteristics that are not easily modified' (p. 1062). Prior research with the SCORS, however, has shown sensitivity to change in internal representations (Fowler, Ackerman, Speanburg, Bailey, \& Blagys, 2004; Porcerelli, Shahar, Blatt, Ford, Mezza, \& Greenlee, 2006). It is possible that explicit self-report measures may be particularly useful as assessment tools of more stable personality characteristics, while narrative-based methods like the SCORS may have excellent utility for understanding change as a function of therapy over time.

There were several limitations to our study. One limitation is that some meaningful relationships might have been missed due to limited statistical power. While there were several notable trends, only 6 of 36 correlations reached the level of statistical significance. Thus, it would be useful to replicate the findings described here using a larger clinical sample. In addition, generalizability of our findings is somewhat limited given the sample size and the fact that the preponderance of patients in our sample 
was single women, and many had Axis II traits. Additionally, we were not able to use two of the SCORS variables (e.g., EIM and ICS) in the present study due to poor reliability. While the SCORS has been repeatedly shown to be a reliable measure (Eudell-Simmons, Stein, DeFife, \& Hilsenroth, 2005; Fowler, Hilsenroth, \& Handler, 1995; Fowler et al., 2004; Porcerelli, Cogan, \& Hibbard, 1998; Stein et al., 2007), reliability for these two variables were questionable in the present study and thus unavailable for use. This is particularly unfortunate with regards to EIM, which we expected would differ considerable across attachment types.

In considering the number of magnitude and number of significant correlations, a few comments are in order. It is important to note that it is common for explicit selfreport measures, such as the RQ and ECR-R, and more implicit-based measures, such as the SCORS-G, to show only a limited relationship to one another as a result of cross-method assessment (Bornstein, 2002; McClelland, Koestner, \& Weinberger, 1989). Kagan (1988) and Meyer and Archer (2001) highlight the importance of recognizing the influence of methods used to assess specified constructs (i.e., clinician-rated versus self-attributed). They posit that the goal be to empirically clarify what each method accomplishes for clinical practice. In this case, the $\mathrm{RQ}$ and ECR-R are assessing patients' self-representation as they report them (Meyer, 1996; Hiller et al., 1999), whereas the SCORS is targeting object representational and behavioural themes derived from coded narratives. Thus, it would make sense that the measures would not be correlated highly with each other. This is also another reason why we highlight and report both significant correlations in addition to trends $(r \leq 0.10)$.

Despite the limitations just described, this study contributes to the attachment/object relations literature in multiple ways. First, this is one of the first studies to examine attachment and object relations in a clinical sample. The present study made use of a naturalistic treatment-seeking clinical sample and thus extends previous research by confirming some findings that were previously studied in non-clinical samples. While some results were consistent with previous studies using nonclinical samples were observed, it is also important to note that results regarding Fearful attachments differed from prior work. They also suggest that many relationships between object relations and attachment may hold even when the individual is distressed. Findings regarding attachment security and attachment anxiety were generally as expected in our clinical setting and similar to results obtained with non-clinical settings. In addition, this is the first study we are aware of to examine the relationships between the RQ and ECR-R in a clinical sample. Results revealed that the relationship between $R Q$ attachment prototype scores and ECR-R attachment dimensional scores were as would be anticipated (Brennan et al., 1998), supporting the use of both instruments in clinical settings.

\section{REFERENCES}

Ackerman, S.J., Clemence, A.J., Weatherhill, R., \& Hilsenroth, M.J. (1999). Use of the TAT in the assessment of DSM-IV cluster B personality disorders. Journal of Personality Assessment, 73(3), 422-448.

Agrawal, H.R., Gunderson, J., Holmes, B.M., \& Lyons-Ruth, K. (2004). Attachment studies with borderline patients: A review. Harvard Review of Psychiatry, 12(2), 94-104.

Ainsworth, M.D.S., Blehar, M.C., Waters, E., \& Wall, S. (1978). Patterns of attachment: Assessed in the Strange Situation and at home. Hillsdale, NJ: Erlbaum.

Ainsworth, M.D.S. (1982). Attachment: Retrospect and prospect. In C.M. Parkes, \& J. Stevenson-Hinde (Eds), The place of attachment in human behavior (pp. 3-30). New York: Basic Books.

Ainsworth, M.D.S. (1989). Attachments beyond infancy. American Psychologist, 44, 709-716.

Ainsworth, M.S., \& Bowlby, J. (1991). An ethological approach to personality development. American Psychologist, 46, 333-341.

Bartholomew, K., \& Horowitz, L.M. (1991). Attachment styles in young adults: A test of a four-category model. Journal of Personality and Social Psychology, 62, 226-244.

Bartholomew, K., \& Shaver, P.R. (1998). Methods of assessing adult attachment: Do they converge? In J.A. Simpson, \& W.S. Rholes (Eds), Attachment theory and close relationships (pp. 25-45). New York: Guilford.

Blatt, S.J., Chevron, S.E., Quinlan, D.M., Schaffer, C.E., \& Wein, S. (1992). The assessment of qualitative and structural dimensions of object representations. Yale University, Unpublished manuscript.

Blatt, S.J., \& Levy, K.N. (2003). Attachment theory, psychoanalysis, personality development, and psychopathology. Psychoanalytic Inquiry, 23(1), 102-150.

Bornstein, R.F. (2002). A process dissociation approach to objective-projective test score interrelationships. Journal of Personality Assessment, 78(1), 47-68.

Bowlby, J. (1973). Attachment and loss: Vol. 2. Separation: Anxiety and anger. New York: Basic Books.

Bowlby, J. (1977). The making and breaking of affectional bonds. British Journal of Psychiatry, 130, 201-210.

Bowlby, J. (1980). Attachment and Loss: Vol. 3. Sadness and depression. New York: Basic Books.

Bowlby, J. (1982). Attachment and loss: Vol. 1. Attachment. (2nd ed.). New York: Basic Books (original work published 1969).

Brennan, K.A., Clark, C.L., \& Shaver, P.R. (1998). Self-report measurement of adult attachment: An integrative overview. In J.A. Simposon, \& W.S. Rholes (Eds), Attachment theory and close relationships (pp. 46-76). New York, NY: Guilford Press.

Buelow, G., McClain, M., \& McIntosh, I. (1996). A new measure for an important construct: The attachment of object relations inventory. Journal of Personality Assessment, 66, 604-623.

Calabrese, M.L., Farber, B.A., \& Westen, D. (2005). The relationship of adult attachment constructs to object relational patterns of representing the self and others. Journal of the American Academy of Psychoanalysis and Dynamic Psychiatry, 33, 513-530.

Carnelley, K.B., Pietromonaco, P.R., \& Jaffe, K. (1994). Depression, working models of others, and relationship functioning. Journal of Personality and Social Psychology, 66, 127-140. 
Collins, N.L., \& Read, S.J. (1990). Adult attachment, working models, and relationship quality in dating couples. Journal of Personality and Social Psychology, 58, 644-663.

Cassidy, J. (1998). Attachment and object relations theories and the concept of independent behavioral systems. Social Development, 7, 120-126.

Crawford, T.N., Shaver, P.R., Cohen, P., Pilkonis, P.A., Gillath, O., \& Kasen, S. (2006). Self-reported attachment, interpersonal aggression, and personality disorder in a prospective community sample of adolescents and adults. Journal of Personality Disorders, 20(4), 331-351.

Davila, J., \& Levy, K.N. (2006). Introduction to the special section on attachment and psychotherapy. Journal of Consulting and Clinical Psychology, 74, 989-993.

Diamond, D., \& Blatt, S.J. (1994). Attachment in Adults: Clinical and Developmental Perspectives. In M.B. Sperling, \& W.H. Berman (Eds) (pp. 72-97). New York, NY: Guilford Press.

Eagle, M. (2006). Attachment, Psychotherapy, and Assessment: A Commentary. Journal of Consulting and Clinical Psychology, 74(6), 1086-1097.

Eames, V., \& Roth, A. (2000). Patient attachment orientation and the early working alliance: A study of patient and therapist reports on alliance quality and ruptures. Psychotherapy Research, 10, 421-434.

Farber, B.A., Lippert, R.A., \& Nevas, D. (1995). The therapist as attachment figure. Psychotherapy, 32, 204-212.

Finn, S.E., \& Tosanger, M.E. (1992). The therapeutic effects of providing MMPI-2 test feedback to college students awaiting psychotherapy. Psychological Assessment, 4, 278-287.

Finn, S.E., \& Tosanger, M.E. (1997). Information-gathering and therapeutic models of assessment: Complementary paradigms. Psychological Assessment, 9, 374-385.

Fischer, C.T. (1994). Individualizing psychological assessment. Mahwah, NJ: Lawrence Erlbaum Associates.

Fonagy, P., Steele, H., \& Steele, M. (1991). Maternal representations of attachment during pregnancy predict the organization of infant-mother attachment at one year of age. Child Development, 62, 891-905.

Fowler, J.C., Hilsenroth, M.J., \& Handler, L. (1995). Early memories: An exploration of theoretically derived queries and their clinical utility. Bulletin of the Menninger Clinic, 52, 31-52.

Fowler, J.C., Ackerman, S., Speanburg, S., Bailey, A., \& Blagys, M. (2004). Personality and symptoms change in treatment refractory inpatients: Evaluation of the phase model of change using Rorschach, TAT, and DSM-IV Axis V. Journal of Personality Assessment, 83, 306-322.

Fraley, R.C., \& Shaver, P.R. (1998). Airport separations: A naturalistic study of adult attachment dynamics in separating couples. Journal of Personality and Social Psychology, 75, 1198-1212.

Fraley, R.C., Waller, N.G., \& Brennan, K.A. (2000). An itemresponse theory analysis of self-report measures of adult attachment. Journal of Personality and Social Psychology, 78, 350-365.

Fraley, R.C., \& Spieker, S.J. (2003). Are infant attachment patterns continuously or categorically distributed? A taxometric analysis of strange situation behavior. Developmental Psychology, 39, 387-404.

Fraley, R.C., \& Waller, N.G. (1998). Adult attachment patterns: A test of the typological model. In J.A. Simposon, \& W.S. Rholes (Eds), Attachment theory and close relationships (pp. 77-114). New York, NY: Guilford Press.
Grotstein, J.S. (1990). The contribution of attachment theory and self-regulation theory to the therapeutic alliance. Modern Psychoanalysis, 15, 169-184.

Hazan, C., \& Shaver, P.R. (1987). Romantic love conceptualized as an attachment process. Journal of Personality and Social Psychology, 59, 270-280.

Hiller, J.B., Rosenthal, R., Bornstein, R.F., Berry, D.T.R., \& Brunell-Neuleib, S. (1999). A comparative meta-analysis of Rorschach and MMPI validity. Psychological Assessment, 11(3), 278-296.

Hilsenroth, M. (2007). A programmatic study of short-term psychodynamic psychotherapy: Assessment, process, outcome and training. Psychotherapy Research, 17(1), 31-45.

Hilsenroth, M., Stein, M., \& Pinsker, J. (2007). Social Cognition and Object Relations Scale: Global Rating Method (SCORS-G). Unpublished manuscript. The Derner Institute of Advanced Psychological Studies, Adelphi University, Garden City, NY.

Holmes, J. (2010). Exploring in security: Towards an attachmentinformed psychoanalytic psychotherapy. New York, NY: Routledge/Taylor \& Francis Group.

Kagan, J. (1988). The meaning of personality predicates. American Psychologist, 43, 614-620.

Keelan, J.P.R., Dion, K.K., \& Dion, K.L. (1998). Attachment style and relationship satisfaction: Test of a self-disclosure explanation. Canadian Journal of Behavioural Science/Revue canadienne des sciences du comportement, 30(1), 24-35.

Kobak, R.R., Cole, H.E., Ferenz-Gillies, R., \& Fleming, W.S. (1993). Attachment and emotion regulation during motherteen problem solving: A control theory analysis. Child Development, 64(1), 231-245.

Levy, K.N., Blatt, S.J., \& Shaver, P.R. (1998). Attachment styles and parental representations. Journal of Personality and Social Psychology, 74, 407-419.

Levy, M.B., \& Davis, K.E. (1988). Love styles and attachment styles compared: Their relations to each other and to various relationship characteristics. Journal of Social and Personal Relationships, 5, 439-471.

Makinen, J.A., \& Johnson, S.M. (2006). Resolving attachment injuries in couples using EFT: Steps toward forgiveness and reconciliation. Journal of Consulting and Clinical Psychology, 74, 1055-1064.

Mallincrodt, B., Porter, M.J., \& Kivlighan, M., Jr. (2005). Client attachment to therapist, depth of in-session exploration, and object relations in brief therapy. Psychotherapy: Theory, Research, Practice, Training, 42, 85-100.

Mallinckrodt, B., Gantt, D.L., \& Coble, H.M. (1995). Attachment patterns in the psychotherapy relationships: Development of the client attachment to therapist scale. Journal of Counseling Psychology, 42, 307-317.

McClelland, D., Koestner, R., \& Weinberger, J. (1989). How do self-attributed and implicit motives differ? Psychological Review, 96(4), 690-702.

Meyer, G.J. (1996). The Rorschach and MMPI: Toward a more scientifically differentiated understanding of cross-method assessment. Journal of Personality Assessment, 67(3), 558-578.

Meyer, G., \& Archer, R. (2001). The Hard Science of Rorschach Research: What do we know and where do we go? Psychological Assessment, 13(4), 486-502.

Mikulincer, M., \& Nachshon, O. (1991). Attachment styles and patterns of self-disclosure. Journal of Personality and Social Psychology, 61(2), 321-331.

Mikulincer, M., \& Orbach, I. (1995). Attachment styles and repressive defensiveness: The accessibility and architecture of 
affective memories. Journal of Personality and Social Psychology, 68(5), 917-925.

Mikulincer, M., \& Shaver, P.R. (2003). The attachment behavioral system in adulthood: Activation, psychodynamics, and interpersonal processes. In M.P. Zanna (Ed.), Advances in experimental social psychology (Vol. 35, pp. 53-152). San Diego, CA: Academic Press.

Mikulincer, M., Orbach, I., \& Iavnieli, D. (1998). Adult attachment style and affect regulation: Strategic variations in subjective self-other similarity. Journal of Personality and Social Psychology, 75, 436-448.

McWilliams, N. (1994). Psychoanalytic diagnosis. New York: Guilford Press.

Peters E.J., Hilsenroth, M.J., Eudell-Simmons, E.M., Blagys, M.D., \& Handler, L (2006). Reliability and validity of the Social Cognition and Object Relations Scale in clinical use. Psychotherapy Research, 16(5), 617-626.

Pistole, M.C. (1989). Attachment in adult romantic relationships: Style of conflict resolution and relationship satisfaction. Journal of Social and Personal Relationships, 6, 505-512.

Porcerelli, J., Cogan, R., \& Hibbard, S. (1998). Cognitive and affective representations of people and MCMI-II personality psychotherapy. Journal of Personality Assessment, 70, 535540.

Porcerelli, J.H., Shahar, G., Blatt, S.J., Ford, R.Q., Mezza, J.A., \& Greenlee, L.M. (2006). Social Cognition and Object Relations Scale: Convergent validity and changes following intensive inpatient treatment. Personality and Individual Differences, 41(3), 407-417.

Priel, B., \& Besser, A. (2001). Bridging the gap between attachment and object relations theories: A study of the transition to motherhood. British Journal of Medical Psychology, 74, 85-100.

Rholes, W.S., \& Simpson, J.A. (2004). Attachment theory: Basic concepts and contemporary questions. In W.S. Rholes, \& J.A. Simpson (Eds), Adult attachment: Theory, research, and clinical applications (pp. 3-14). New York: Guilford.
Schmitt, D.P., Diniz, G., Alcalay, L., Durkin, K., \& Allensworth, M., et al. (2004). Patterns and universals of adult romantic attachment across 62 cultural regions: Are models of self and of other pancultural constructs. Journal of Cross-Cultural Psychology, 35(4), 367-402.

Shaver, P.R., \& Mikulincer, M. (2002). Attachment-related psychodynamics. Attachment \& Human Development, 4, 133-161.

Shaver, P.R., \& Mikulincer, M. (2005). Attachment theory and research: Resurrection of the psychodynamic approach to personality. Journal of Research in Personality, 39(1), 22-45.

Shrout, P.E., \& Fleiss, J.L. (1979). Intraclass correlations: Uses in assessing rater reliability. Psychological Bulletin, 86(2), 420-428.

Slade, A., \& Aber, J.L. (1992). Attachments, drives, and development: Conflicts and convergences in theory. In J.W. Barron, M.N. Eagle, \& D.L. Wolitzky (Eds.), Interface of psychoanalysis and psychology (pp. 154-185). Washington, DC: American Psychological Association.

Steele, H., \& Steele, M. (1998). Attachment and psychoanalysis: Time for a reunion. Social Development, 7, 92-119.

Stein, M., Pinsker, J., \& Hilsenroth, M. (2007). Borderline Pathology and the Personality Assessment Inventory (PAI): An evaluation of criterion and concurrent validity. Journal of Personality Assessment, 88(1), 81-89.

West, M., Sheldon, A., \& Reiffer, L. (1987). An approach to the delineation of adult attachment: Scale development and rehabilitation. Journal of Nervous and Mental Disease, 181, 422-427.

West, M., \& Sheldon-Keller, A.E. (1994). Patterns of relating: An adult attachment perspective. New York: Guilford Press.

Westen, D. (1995). Social Cognition and Object Relations Scale: Q-sort for Projective Stories (SCORS-Q). Unpublished manuscript; Department of Psychiatry, The Cambridge Hospital and Harvard Medical School, Cambridge, MA

Westen, D., Barends, A., Leigh, J., Mendel, M., \& Silbert, D. (1994). Social cognition and object relations scale (SCORS): Manual for coding interview data. Unpublished manuscript, Harvard university, Cambridge, MA. 